\title{
Thermal decomposition analysis of simulated high-level liquid waste in cold-cap
}

\author{
Kota Kawai , Tatsuya Fukuda, Yoshio Nakano, and Kenji Takeshita \\ Research Laboratory for Nuclear Reactor, Tokyo Institute of Technology, 2-12-1-N1-2, Ookayama, Meguro-ku, Tokyo 152-8550, \\ Japan
}

Received: 19 October 2015 / Received in final form: 30 September 2016 / Accepted: 8 November 2016

\begin{abstract}
The cold cap floating on top of the molten glass pool in liquid fed joule-heated ceramic melter plays an important role for operation of the vitrification process. A series of such phenomena as evaporation, melting and thermal decomposition of HLLW (high-level liquid waste) takes place within the cold-cap. An understanding of the varied thermal decomposition behavior of various nitrates constituting HLLW is necessary to elucidate a series of phenomena occurring within the cold-cap. In this study, reaction rates of the thermal decomposition reaction of 13 kinds of nitrates, which are main constituents of simulated HLLW (sHLLW), were investigated using thermogravimetrical instrument in a range of room temperature to $1000^{\circ} \mathrm{C}$. The reaction rates of the thermal decompositions of 13 kinds of nitrates were depicted according to composition ratio (wt\%) of each nitrate in sHLLW. It was found that the thermal decomposition of sHLLW could be predicted by the reaction rates and reaction temperatures of individual nitrates. The thermal decomposition of sHLLW with borosilicate glass system was also investigated. The above mentioned results will be able to provide a useful knowledge for understanding the phenomena occurring within the cold-cap.
\end{abstract}

\section{Introduction}

In the closed fuel cycles, high-level liquid waste (HLLW) is generated from reprocessing of spent nuclear fuel. HLLW possesses intrinsic characteristics such as decay heat, corrosiveness and generation of hydrogen associated with radiolysis $[1,2]$. Thus, long time storage of HLLW is difficult in terms of confinement and management of radioactive materials because of its liquid state. Therefore, HLLW is immobilized into borosilicate glass matrix for safe long-time storage. The immobilized HLLW is called vitrified waste. Prior to the final disposal in deep geological repository, vitrified waste should be cooled for $30-50$ years to achieve decrease of decay heat.

HLLW contains 31 kinds of nitrates which consist of fission products, $\mathrm{Na}$ from alkaline rinse, $\mathrm{P}$ from TBP degradation products, some insoluble particles such as $\mathrm{Zr}$ fines from the cladding of the fuel elements, Mo and platinum group metals ( $\mathrm{Pd}, \mathrm{Ru}$ and $\mathrm{Rh})$ [3].

In the vitrification process, the cold cap floating on top of the molten glass pool in liquid fed joule-heated ceramic melter plays an important role for its operation. A series of such phenomena as evaporation, melting and thermal decomposition of HLLW takes place within the cold-cap.

\footnotetext{
* e-mail: kawai.k.af@m.titech.ac.jp
}

The contact with glass beads results in further chemical reactions to incorporate all waste constituents, either as oxides of other compounds into the glass structure. The cold-cap formation and conversion to glass take place under non-isothermal conditions in a range of room temperature to $1200^{\circ} \mathrm{C}$. It depends on the processing parameters and properties of the various chemical elements of HLLW. An understanding of the various thermal decomposition behavior of many nitrates constituting HLLW is necessary to elucidate a series of phenomena occurring within the cold-cap. Some works such as developments of simulation model in terms of heat balance, kinetic analysis of reactions, decomposition of individual chemicals used for the UK solution by means of thermal balance and so on have been reported on the study of coldcap [4-9]. However, there are few studies which investigate interaction among constituents of HLLW for cold-cap reaction. In this study, we investigated thermal decomposition of nitrates constituting HLLW at each temperature region under an elevated temperature process by the mean of reaction rate. In addition, the map of thermal decomposition rate vs temperature for the nitrates constituting sHLLW was depicted according to the composition ratio of each nitrate that was contained in sHLLW in a range of room temperature to $1000^{\circ} \mathrm{C}$ in order to simulate the thermal decomposition of sHLLW. Moreover, we investigated effects of addition of borosilicate 
glass for the thermal decomposition behavior of nitrates constituting HLLW in order to simulate practical phenomena occurring in cold-cap. These results lead to further clarification of transport phenomena and reactions occurring over a range of room temperature to $1200^{\circ} \mathrm{C}$ in coldcap.

\section{Experimental}

Table 1 shows the composition of sHLLW used in this study. Composition of HLLW is determined by private communication with Japan Nuclear Fuel Limited which is Japanese reprocessing company based on the book "Nuclear chemical engineering" written by Benedict et al. [10]. The sHLLW was evaporated to dryness on a hot plate at $70{ }^{\circ} \mathrm{C}$ in order to obtain the dried-sHLLW.

The thermal decomposition reaction of 13 kinds of nitrates, which are main constituents of sHLLW (corresponding approximately to $93.3 \mathrm{~mol} \%$ of sHLLW), with different chemical and physical properties were investigated using thermogravimetrical instrument (TG: TGA-50, SHIMADZU). Table 2 shows 13 kinds of reagents. Ru was omitted in this study due to cost, and Mo was also omitted because thermal decomposition of sodium molybdate dehydrate from room temperature to $1000^{\circ} \mathrm{C}$ is only dehydration which is occurring at around $100^{\circ} \mathrm{C} . \mathrm{NaNO}_{2}$ was used as sodium nitrate for the following reasons. Thermal decomposition of sodium nitrate under isothermal conditions at around $600^{\circ} \mathrm{C}$ is sequential reaction, which is $\mathrm{NaNO}_{3} \rightarrow \mathrm{NaNO}_{2} \rightarrow \mathrm{Na}_{2} \mathrm{O}$. The fractional reaction $\alpha$ is defined as $\alpha=\left(m_{\text {ini }}-m_{t}\right) /\left(m_{\text {ini }}-m_{\mathrm{fin}}\right)$; where $m_{\text {ini }}, m_{\mathrm{fni}}$ and $m_{t}$ are the weight at initial, final and a given time, respectively. The $\alpha$ value is 0.295 for $\mathrm{NaNO}_{3} \rightarrow \mathrm{NaNO}_{2}$ reaction step and 0.705 for $\mathrm{NaNO}_{2} \rightarrow \mathrm{Na}_{2} \mathrm{O}$ reaction. The thermal decomposition of sodium nitrate gradually starts from $550^{\circ} \mathrm{C}$ and the sequential reaction cannot be confirmed under non-isothermal $\left(1-10^{\circ} \mathrm{C} / \mathrm{min}\right)$ [11,12]. This suggests that $\mathrm{NaNO}_{3} \rightarrow \mathrm{NaNO}_{2}$ reaction proceeds more rapidly than $\mathrm{NaNO}_{2} \rightarrow \mathrm{Na}_{2} \mathrm{O}$ so that $\mathrm{NaNO}_{2} \rightarrow \mathrm{Na}_{2} \mathrm{O}$ reaction step is rate-limiting reaction. For this reason, as the starting reagent, sodium nitrate $\left(\mathrm{NaNO}_{3}\right)$ is replaced by sodium nitrite $\left(\mathrm{NaNO}_{2}\right)$.

The TG measurements were conducted with heating rate of $5{ }^{\circ} \mathrm{C} / \mathrm{min}$ in a range of room temperature to $1000{ }^{\circ} \mathrm{C}$ at flow rate, $75 \mathrm{~cm}^{3} / \mathrm{min}$ of $\mathrm{N}_{2}$ gas in order to evaluate the thermal decomposition occurring under inert atmosphere. The reaction rates of thermal decomposition of the nitrates were calculated on the basis of the TG curves. The map of their reaction rates and reaction temperatures was described over their reaction temperature ranges under heating rate of $5^{\circ} \mathrm{C} / \mathrm{min}$. In addition, chemical compounds were described in the map. Their compounds are estimated stoichiometrically based on TG curves.

The thermal decomposition reaction of dried-sHLLW and each nitrate included in the dried-sHLLW with borosilicate glass powder were investigated as well. The composition of used borosilicate glass is listed in Table 3, which are determined by private communication with Japan Nuclear Fuel Limited as well. The borosilicate glass beads were ground to powder of $75 \mu \mathrm{m}$ to $100 \mu \mathrm{m}$ in
Table 1. Composition of simulated high-level liquid waste.

\begin{tabular}{lll}
\hline Element & $\begin{array}{l}\text { Concentration } \\
{[\mathrm{mol} / \mathrm{L}]}\end{array}$ & $\begin{array}{l}\text { Oxide concentration } \\
{[\mathrm{g} / \mathrm{L}]}\end{array}$ \\
\hline $\mathrm{H}$ & 1.38 & \\
$\mathrm{Na}$ & 1.005 & 31.1 \\
$\mathrm{Nd}$ & 0.0615 & 10.3 \\
$\mathrm{Zr}$ & 0.0512 & 6.31 \\
$\mathrm{Gd}$ & 0.0364 & 6.6 \\
$\mathrm{Ce}$ & 0.0363 & 6.25 \\
$\mathrm{Cs}$ & 0.0358 & 5.04 \\
$\mathrm{Mo}$ & 0.0321 & 4.62 \\
$\mathrm{Fe}$ & 0.0307 & 2.45 \\
$\mathrm{La}$ & 0.0225 & 3.67 \\
$\mathrm{Ru}$ & 0.0219 & 2.91 \\
$\mathrm{Mn}$ & 0.0189 & 1.34 \\
$\mathrm{Ba}$ & 0.0161 & 2.47 \\
$\mathrm{Pr}$ & 0.0159 & 2.71 \\
$\mathrm{Pd}$ & 0.0155 & 1.9 \\
$\mathrm{Sr}$ & 0.0124 & 1.28 \\
$\mathrm{Sm}$ & 0.00898 & 1.57 \\
$\mathrm{Y}$ & 0.00815 & 0.92 \\
$\mathrm{Cr}$ & 0.0063 & 0.479 \\
$\mathrm{Rh}$ & 0.00501 & 0.636 \\
$\mathrm{P}$ & 0.0043 & 0.305 \\
$\mathrm{Te}$ & 0.00399 & 0.796 \\
$\mathrm{Ni}$ & 0.00109 & 0.814 \\
$\mathrm{Ag}$ & 0.000966 & 0.112 \\
$\mathrm{Others}$ & 0.00483 & 0.2978 \\
\hline
\end{tabular}

Table 2. Used reagent for 13 kinds of elements (Wako: Wako Pure Chemical Industries, Ltd., Kanto: Kanto Chemical Co., Inc.).

\begin{tabular}{llr}
\hline Element & Reagent & Reagent-grade \\
\hline $\mathrm{Na}$ & $\mathrm{NaNO}_{2}$ & $>98.5 \%$, Kanto \\
$\mathrm{Nd}$ & $\mathrm{Nd}\left(\mathrm{NO}_{3}\right)_{3} \cdot 6 \mathrm{H}_{2} \mathrm{O}$ & $99.5 \%$, Wako \\
$\mathrm{Zr}$ & $\mathrm{ZrO}\left(\mathrm{NO}_{3}\right)_{2} \cdot 2 \mathrm{H}_{2} \mathrm{O}$ & $>97.0 \%$, Wako \\
$\mathrm{Gd}$ & $\mathrm{Gd}\left(\mathrm{NO}_{3}\right)_{3} \cdot 6 \mathrm{H}_{2} \mathrm{O}$ & $99.5 \%$, Wako \\
$\mathrm{Ce}$ & $\mathrm{Ce}\left(\mathrm{NO}_{3}\right) \cdot 6 \mathrm{H}_{2} \mathrm{O}$ & $>98.0 \%$, Wako \\
$\mathrm{Cs}$ & $\mathrm{CsNO}$ & $99.9 \%$, Wako \\
$\mathrm{Fe}$ & $\mathrm{Fe}\left(\mathrm{NO}_{3}\right)_{3} \cdot 9 \mathrm{H}_{2} \mathrm{O}$ & $>99.0 \%$, Wako \\
$\mathrm{La}$ & $\mathrm{La}\left(\mathrm{NO}_{3}\right)_{3} \cdot 6 \mathrm{H}_{2} \mathrm{O}$ & $99.9 \%$, Wako \\
$\mathrm{Mn}$ & $\mathrm{Mn}\left(\mathrm{NO}_{3}\right)_{2} \cdot 6 \mathrm{H}_{2} \mathrm{O}$ & $>98.0 \%$, Wako \\
$\mathrm{Ba}$ & $\mathrm{Ba}\left(\mathrm{NO}_{3}\right)_{2}$ & $99.9 \%$, Wako \\
$\mathrm{Pr}$ & $\mathrm{Pr}\left(\mathrm{NO}_{3}\right)_{3} \cdot 6 \mathrm{H}_{2} \mathrm{O}$ & $99.9 \%$, Wako \\
$\mathrm{Pd}$ & $\mathrm{Pd}\left(\mathrm{NO}_{3}\right)_{2}$ & $>97.0 \%$, Wako \\
$\mathrm{Sr}$ & $\mathrm{Sr}\left(\mathrm{NO}_{3}\right)_{2}$ & $>98.0 \%$, Wako \\
\hline
\end{tabular}


Table 3. Composition of borosilicate glass.

\begin{tabular}{ll}
\hline Oxide composition & Concentration ratio [wt\%] \\
\hline $\mathrm{SiO}_{2}$ & 60 \\
$\mathrm{~B}_{2} \mathrm{O}_{3}$ & 18.2 \\
$\mathrm{Al}_{2} \mathrm{O}_{3}$ & 6.4 \\
$\mathrm{Li}_{2} \mathrm{O}$ & 3.8 \\
$\mathrm{CaO}$ & 3.8 \\
$\mathrm{ZnO}$ & 3.8 \\
$\mathrm{Na}_{2} \mathrm{O}$ & 4.0 \\
\hline
\end{tabular}

diameter using an alumina mortar. The weight ratio of dried-sHLLW or nitrate to the borosilicate glass mixture was $40 \mathrm{wt} \%$.

\section{Results and discussion}

\subsection{Thermal decomposition behavior of constituents of simulated HLLW}

Figure 1 shows the reaction rate of thermal decomposition of iron nitrate $\left[\mathrm{Fe}\left(\mathrm{NO}_{3}\right)_{3} \cdot 9 \mathrm{H}_{2} \mathrm{O}\right]$. It was dehydrated to produce $\mathrm{Fe}\left(\mathrm{NO}_{3}\right)_{3}$. Then, it reacted to $\mathrm{Fe}_{2} \mathrm{O}_{3}$ in the low temperature range of 100 to $200{ }^{\circ} \mathrm{C}$.

Figure 2 shows the reaction rate of thermal decomposition of zirconium nitrate $\left[\mathrm{ZrO}\left(\mathrm{NO}_{3}\right)_{2} \cdot 2 \mathrm{H}_{2} \mathrm{O}\right]$. It was dehydrated to $\mathrm{ZrO}\left(\mathrm{NO}_{3}\right)_{2}$ in the range of room temperature to $100{ }^{\circ} \mathrm{C}$. $\mathrm{ZrO}\left(\mathrm{NO}_{3}\right)_{2}$ was decomposed to $\mathrm{Zr}_{2} \mathrm{O}_{3}\left(\mathrm{NO}_{3}\right)$ and finally to $\mathrm{ZrO}_{2}$ in the range of 100 to $400{ }^{\circ} \mathrm{C}$.

Figure 3 shows the reaction rate of thermal decomposition of gadolinium nitrate $\left[\mathrm{Gd}\left(\mathrm{NO}_{3}\right)_{3} \cdot 6 \mathrm{H}_{2} \mathrm{O}\right]$. It was dehydrated to $\mathrm{Gd}\left(\mathrm{NO}_{3}\right)_{3}$ at around room temperature to $300{ }^{\circ} \mathrm{C}, \mathrm{Gd}\left(\mathrm{NO}_{3}\right)_{3}$ was decomposed to $\mathrm{GdONO}_{3}$ at around $400^{\circ} \mathrm{C}$, finally to $\mathrm{Gd}_{2} \mathrm{O}_{3}$. Reaction step $1\left(\mathrm{Gd}\left(\mathrm{NO}_{3}\right)_{3} \rightarrow\right.$ $\left.\mathrm{GdONO}_{3}\right)$, step $2\left(\mathrm{GdONO}_{3} \rightarrow \mathrm{Gd}_{2} \mathrm{O}_{3}\right)$ proceeded sequentially at around $400^{\circ} \mathrm{C}(\mathrm{STEP} 1), 500^{\circ} \mathrm{C}$ to $600{ }^{\circ} \mathrm{C}(\mathrm{STEP}$ $2)$, respectively.

Figure 4 shows the reaction rate of thermal decomposition of $\mathrm{NaNO}_{2}$. It was decomposed to $\mathrm{Na}_{2} \mathrm{O}$ in the region above $600^{\circ} \mathrm{C}$. Furthermore, $\mathrm{Na}_{2} \mathrm{O}$ is sublimated above a temperature of $800^{\circ} \mathrm{C}$. The thermal decomposition of other 9 kinds of nitrates were also investigated as well. The results are summarized in Table 4. Iron nitrate was decomposed in the temperature region lower than $200^{\circ} \mathrm{C}$. The nitrates of lanthanoid series such as lanthanum, neodymium and gadolinium nitrate were decomposed in the middle range of 200 to $600^{\circ} \mathrm{C}$. Alkali metal and alkaline-earth metal such as strontium, cesium, barium and sodium were decomposed in the high temperature region of 600 to $1000^{\circ} \mathrm{C}$.

In Figure 5, the reaction rates of the thermal decompositions of 13 nitrates were depicted according to composition ratio (wt\%) of each nitrate in a range of room temperature to $1000^{\circ} \mathrm{C}$. The presence of $\mathrm{Na}$ is dominant in sHLLW as shown in Table 1 . The reaction rate curves for 13 nitrates were superimposed on a graph of reaction rates vs temperature, as shown by a red line in Figure 6. The reaction rate curve observed from thermal

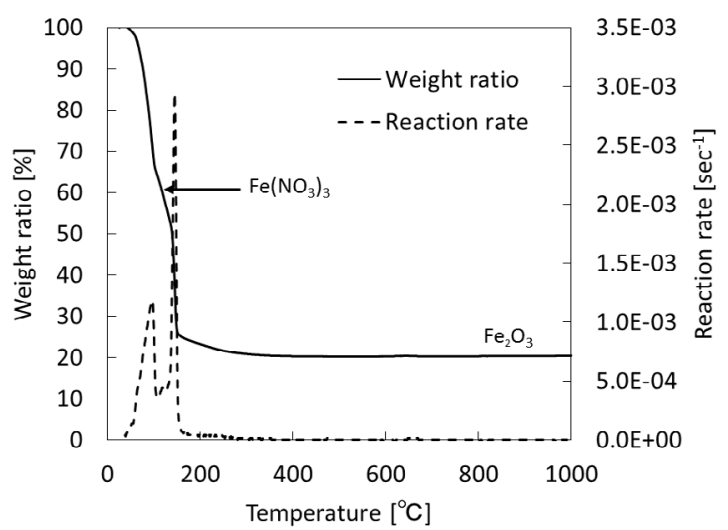

Fig. 1. TG curve and reaction rate of the thermal decomposition of $\mathrm{Fe}\left(\mathrm{NO}_{3}\right)_{3} \cdot 9 \mathrm{H}_{2} \mathrm{O}$ at heating rate of $5^{\circ} \mathrm{C} / \mathrm{min}$.

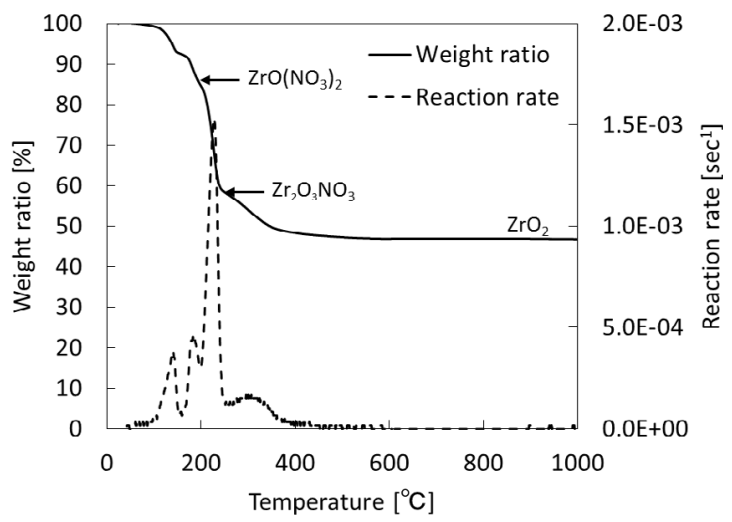

Fig. 2. TG curve and reaction rate of the thermal decomposition of $\mathrm{ZrO}\left(\mathrm{NO}_{3}\right)_{2} \cdot 2 \mathrm{H}_{2} \mathrm{O}$ at heating rate of $5{ }^{\circ} \mathrm{C} / \mathrm{min}$.

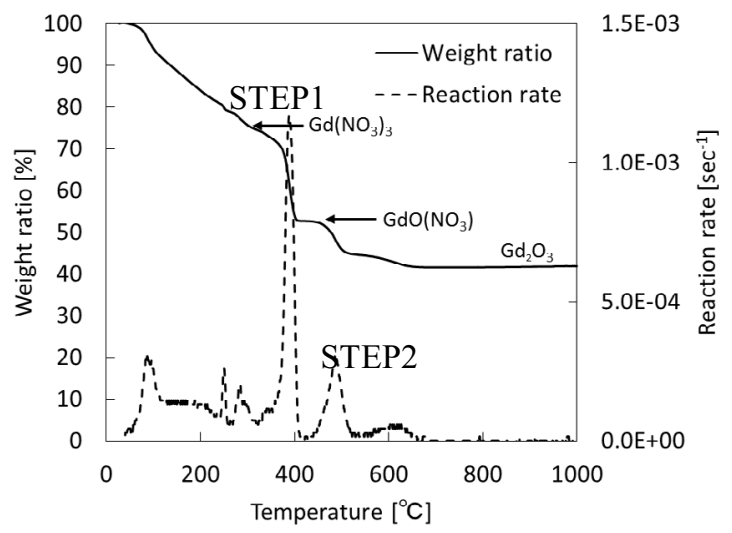

Fig. 3. TG curve and reaction rate of the thermal decomposition of $\mathrm{Gd}\left(\mathrm{NO}_{3}\right)_{3} \cdot 6 \mathrm{H}_{2} \mathrm{O}$ at heating rate of $5^{\circ} \mathrm{C} / \mathrm{min}$.

decomposition of dried-sHLLW (black line) was also depicted in the same figure. As a result, the characteristic peaks of thermal decomposition of dried-sHLLW were fitted with overlapped reaction rates of thermal decomposition of their nitrates, especially the peaks around $400{ }^{\circ} \mathrm{C}$ and $750{ }^{\circ} \mathrm{C}$ corresponding to thermal decomposition of lanthanum nitrates and sodium nitrate. However, 


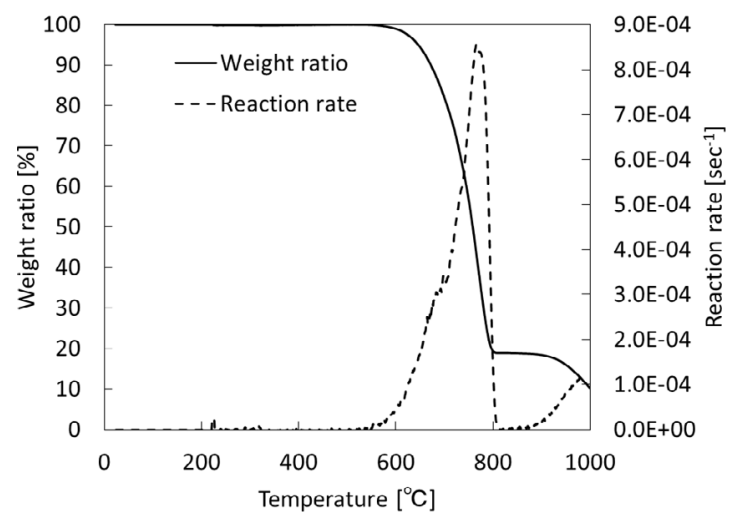

Fig. 4. TG curve and reaction rate of the thermal decomposition of $\mathrm{NaNO}_{2}$ at heating rate of $5^{\circ} \mathrm{C} / \mathrm{min}$.

the disappearance of iron nitrate decomposition peak and the appearance of peaks at $300^{\circ} \mathrm{C}$ and $600{ }^{\circ} \mathrm{C}$ were observed in Figure 6 . It is assumed that iron nitrate is decomposed with other chemical substances and thermal decomposition of alkali and alkaline-earth metal nitrates was promoted with other chemical substances at $600{ }^{\circ} \mathrm{C}$. Especially, contribution of decomposition of sodium nitrate would be dominant. Therefore, it was found that the thermal decomposition of dried-sHLLW could be predicted from the relation between the reaction rates and reaction temperatures for their nitrates. Investigation of disappearance and appearance of peaks is a challenge for the future.

\subsection{Thermal decomposition behavior of constituents/ borosilicate glass system}

In the cold-cap floating on molten glass, HLLW and borosilicate glass coexist. Studying their interaction is necessary to understand a series of phenomena occurring within the cold-cap. Then, the thermal decomposition of

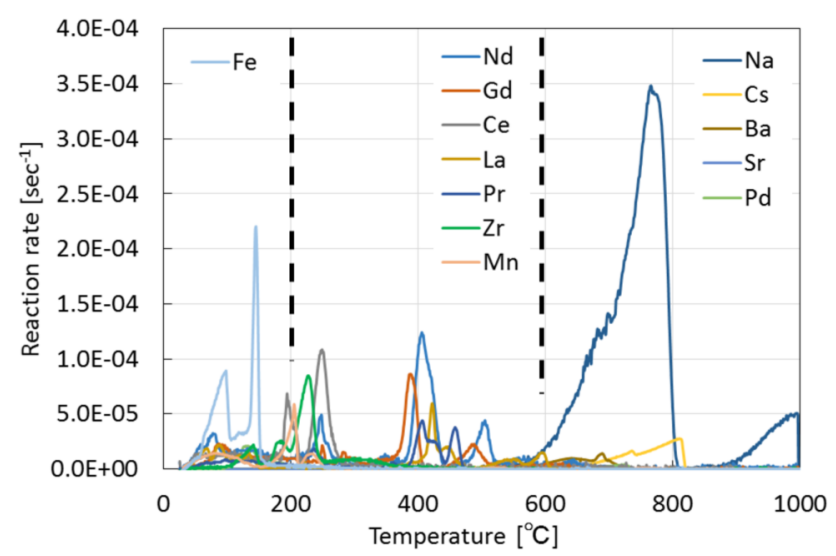

Fig. 5. Thermal decomposition rate of 13 kinds of nitrates at heating rate of $5{ }^{\circ} \mathrm{C} / \mathrm{min}$, which were depicted according to composition ratio of each nitrate in sHLLW.

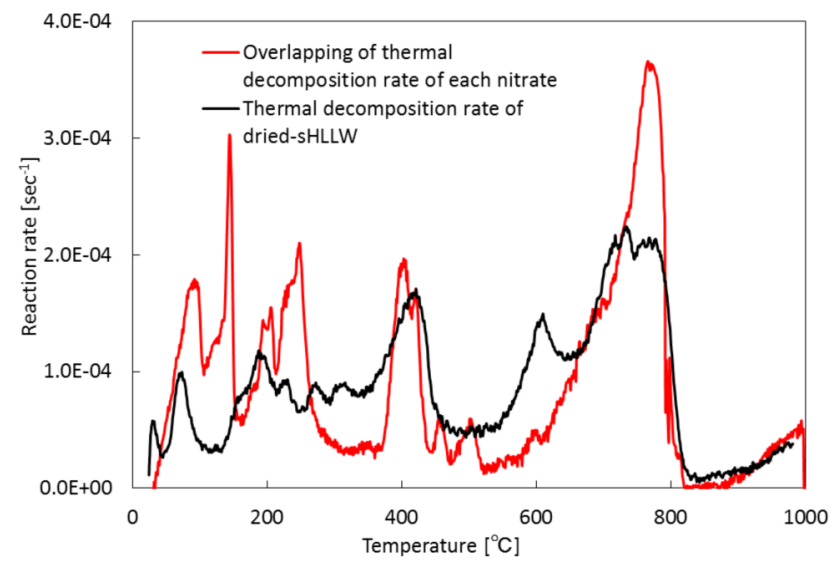

Fig. 6. Comparison between the thermal decomposition rate of sHLLW (black line) and that overlapping thermal decomposition rates of 13 kinds of nitrates included in sHLLW (red line).

Table 4. Map of reaction property vs. temperature.

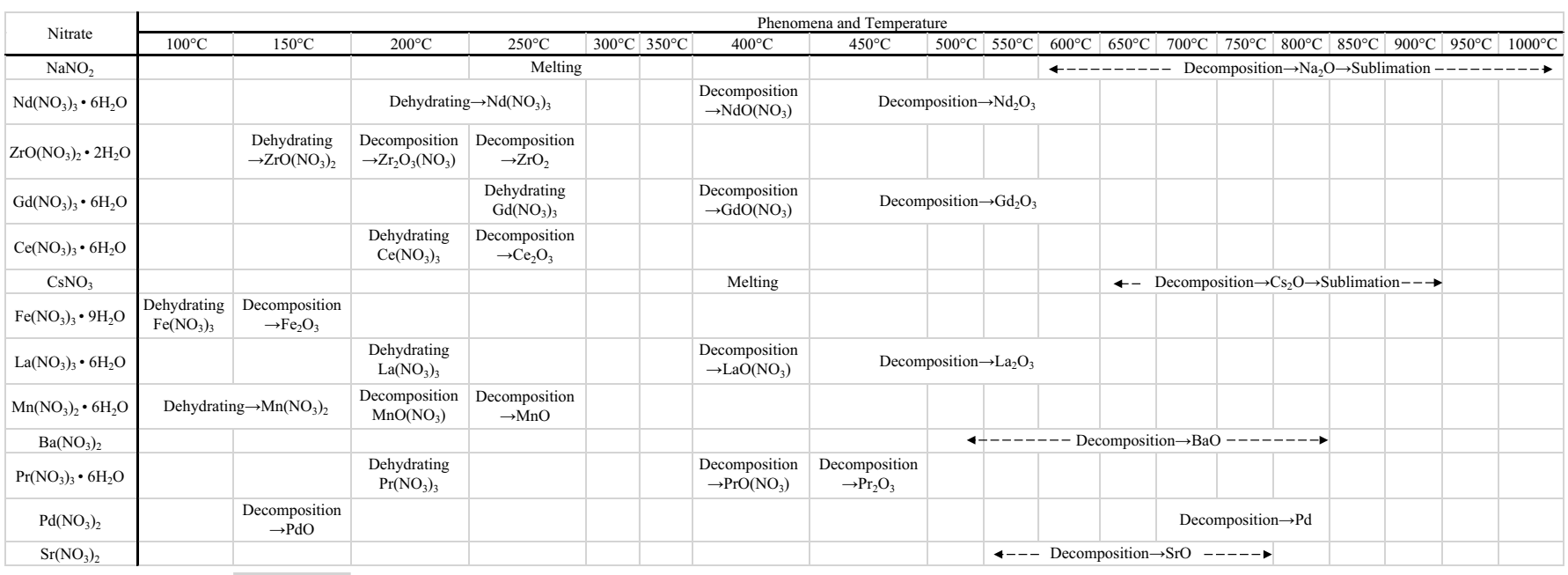


13 nitrates coexisting with borosilicate glass powder (75 to $100 \mu \mathrm{m}$ in diameter) was investigated by the same way as that described in the former section.

Figure 7 shows the thermal decomposition rate of $\mathrm{NaNO}_{2}$ with borosilicate glass powder in a range of room temperature to $800^{\circ} \mathrm{C}$. The weight ratio, the vertical axis in the figure, means the ratio of weight of remaining $\mathrm{NaNO}_{2}$ to initial weight. Then, it was assumed that the weight of borosilicate glass powder is constant during the reaction. Thermal decomposition of $\mathrm{NaNO}_{2}$ in the presence of borosilicate glass powder took place at much lower temperature than that of the sodium nitrite itself (Fig. 4). Similar phenomena were reported by Abe et al. [13]. From the viewpoint of thermodynamics, the following chemical reactions can occur in the presence of borosilicate glass. These reactions indicate that the thermal decomposition of sodium nitrite is promoted and occurring at low temperature.

\section{STEP 1}

$$
\begin{gathered}
2 \mathrm{NaNO}_{2}=\mathrm{Na}_{2} \mathrm{O}_{2}+2 \mathrm{NO} \\
\mathrm{Na}_{2} \mathrm{O}_{2}+\mathrm{NaNO}_{2}=\mathrm{Na}_{2} \mathrm{O}+\mathrm{NaNO}_{3} \\
\mathrm{Na}_{2} \mathrm{O}+\mathrm{B}_{2} \mathrm{O}_{3}=\mathrm{Na}_{2} \mathrm{O} \cdot \mathrm{B}_{2} \mathrm{O}_{3}
\end{gathered}
$$

STEP 2

$$
\begin{gathered}
3 \mathrm{NaNO}_{2}=\mathrm{NaNO}_{3}+\mathrm{Na}_{2} \mathrm{O}+2 \mathrm{NO} \\
2 \mathrm{NaNO}_{2}=\mathrm{Na}_{2} \mathrm{O}_{2}+2 \mathrm{NO} \\
\mathrm{Na}_{2} \mathrm{O}_{2}=\mathrm{Na}_{2} \mathrm{O}+\frac{1}{2} \mathrm{O}_{2} \\
\mathrm{Na}_{2} \mathrm{O}+\mathrm{SiO}_{2}=\mathrm{Na}_{2} \mathrm{O} \cdot \mathrm{SiO}_{2}
\end{gathered}
$$

\section{STEP 3}

$$
\begin{gathered}
2 \mathrm{NaNO}_{3}=\mathrm{Na}_{2} \mathrm{O}_{2}+2 \mathrm{NO}+\mathrm{O}_{2} \\
\mathrm{Na}_{2} \mathrm{O}_{2}=\mathrm{Na}_{2} \mathrm{O}+\frac{1}{2} \mathrm{O}_{2} \\
2 \mathrm{NaNO}_{3}=\mathrm{Na}_{2} \mathrm{O}+2 \mathrm{NO}+\frac{3}{2} \mathrm{O}_{2} \\
\mathrm{Na}_{2} \mathrm{O}+\mathrm{SiO}_{2}=\mathrm{Na}_{2} \mathrm{O} \cdot \mathrm{SiO}_{2} .
\end{gathered}
$$

Moreover, $\mathrm{Na}_{2} \mathrm{O}$ may not be sublimated in the presence of borosilicate glass as shown in Figure 7. For other alkali metal and alkaline-earth metal nitrates, the thermal decomposition of their nitrates also took place at lower temperatures due to the presence of borosilicate glass powder.

Figure 8 shows the thermal decomposition rate of gadolinium nitrate in the presence of borosilicate glass powder. In this case, the behavior of its thermal decomposition is similar to the case without borosilicate

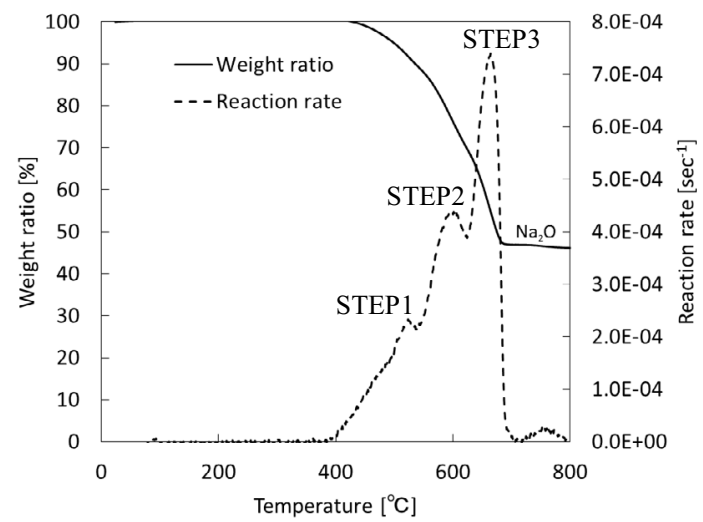

Fig. 7. TG curve obtained by the thermal decomposition of $\mathrm{NaNO}_{2}$ in the presence of borosilicate glass powder at heating rate of $5{ }^{\circ} \mathrm{C} / \mathrm{min}$ (solid line) and the thermal decomposition rate calculated from the differential of the TG curve (dashed line).

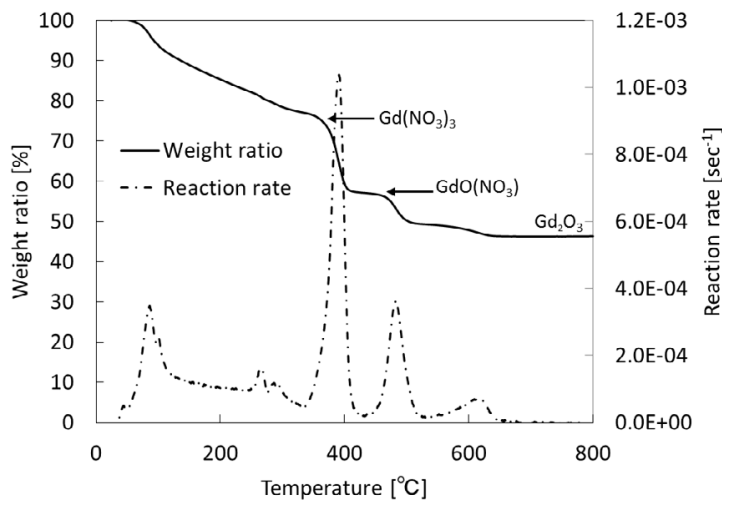

Fig. 8. TG curve obtained by the thermal decomposition of $\mathrm{Gd}$ $\left(\mathrm{NO}_{3}\right)_{3} \cdot 6 \mathrm{H}_{2} \mathrm{O}$ in the presence of borosilicate glass powder at heating rate of $5^{\circ} \mathrm{C} / \mathrm{min}$ (solid line) and the thermal decomposition rate calculated from the differential of the TG curve (dashed line).

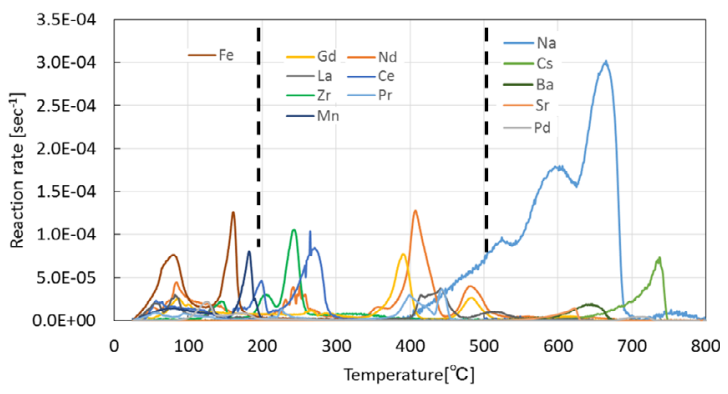

Fig. 9. Thermal decomposition rate of 13 kinds of nitrates in the presence of borosilicate glass powder at heating rate of $5{ }^{\circ} \mathrm{C} / \mathrm{min}$, which are depicted according to composition ratio of each nitrate in SHLLW.

glass described in Figure 3. Thus, the effects by the addition of borosilicate glass were not observed. For other lanthanides and iron nitrates, the effects of the addition of borosilicate glass were not observed as well.

Figure 9 shows the thermal decompositions rates of 13 nitrates in the presence of borosilicate glass powder, which were depicted according to composition ratio (wt\%) of each 


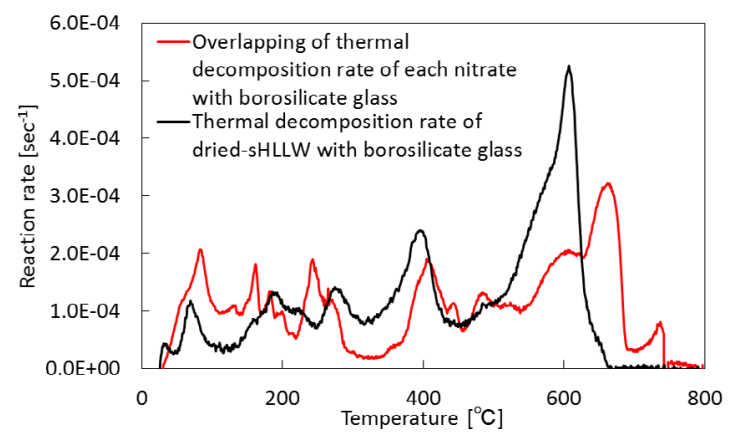

Fig. 10. Comparison between the thermal decomposition rate of sHLLW (black line) and that obtained by overlapping the thermal decomposition rates of 13 kinds of nitrates (red line) in the presence of borosilicate glass powder.

nitrate. The temperature range was from room temperature to $800^{\circ} \mathrm{C}$. In order to compare the thermal decomposition of dried-sHLLW and those of 13 nitrates in the presence of borosilicate glass, the overlapping curve of the thermal decomposition rates of 13 nitrates in the presence of borosilicate glass powder is shown with a red line in Figure 10. The thermal decomposition rate of driedsHLLW in the presence of borosilicate glass powder is shown with a black line in the same figure. The decomposition rates of dried-sHLLW below $500^{\circ} \mathrm{C}$ were not changed with and without borosilicate glass. However, the thermal decomposition rates of dried-sHLLW in the presence of borosilicate glass powder above $500{ }^{\circ} \mathrm{C}$ is dramatically changed compared to the overlapping of the thermal decomposition rates of 13 nitrates in the presence of borosilicate glass powder, especially the part of the sodium nitrate decomposition with glass powder. In Figure 10, there are no peak corresponding to STEP 3 in Figure 7. It seems that the sodium nitrate decomposition was promoted by the presence of other chemical substances included in sHLLW. Although the thermal decomposition of dried-sHLLW with borosilicate glass powder tends to occur at lower temperature than that of sHLLW above $500{ }^{\circ} \mathrm{C}$, the thermal decomposition rate of dried-sHLLW with borosilicate glass powder could be described by overlapping the thermal decomposition rates of 13 nitrates. Investigation of interaction between sodium nitrate and other chemical substances in the presence of borosilicate glass is also a challenge for the future as well as the former section.

\section{Conclusions}

The thermal decomposition of 13 nitrates which are main constituents of sHLLW was investigated using thermalgravimetrical analysis in the range of room temperature to $1000{ }^{\circ} \mathrm{C}$. At the low temperature range of room temperature to $200^{\circ} \mathrm{C}$, iron and palladium nitrates decomposed to oxide. At the middle temperature range of 200 to $600{ }^{\circ} \mathrm{C}$, zirconium, manganese and lanthanoid series nitrates decomposed to oxide. At the high temperature range of 600 to $1000{ }^{\circ} \mathrm{C}$, alkali and alkaline-earth metal nitrates decomposed to oxide. The overlapped curve of the thermal decomposition rates for 13 kinds of nitrates, which includes $\mathrm{Na}, \mathrm{Nd}$, Zr, Gd, Ce, Cs, Fe, La, Mn, Ba, Pr, $\mathrm{Pd}$ and $\mathrm{Sr}$, was almost fitted with the curve of the thermal decomposition rate of dried-sHLLW. It was also found that iron nitrate, alkali and alkaline-earth metal nitrates are probably decomposed with other chemical substances included in sHLLW. In addition, the thermal decomposition of each nitrate with borosilicate glass powder was investigated as well. As the results, it was observed that the thermal decomposition of alkali metal and alkalineearth metal nitrates were affected by the borosilicate glass. For other nitrates such as lanthanides, zirconium nitrate, iron nitrate and so on, the effects of their thermal decomposition in the presence of borosilicate glass were not observed. The overlapped curve of the thermal decomposition rates for 13 nitrates with borosilicate glass was fitted roughly with the thermal decomposition rates of dried-sHLLW with borosilicate glass powder. It was found that most of the thermal decomposition behavior of HLLW within the cold-cap is able to be predicted by the thermal decomposition behavior of the individual nitrates which are included in HLLW. The thermal decomposition of sodium nitrate with borosilicate glass powder is promoted due to some reaction with other chemical substances included in sHLLW as well as thermal decomposition of sHLLW. The above results will be able to provide a useful knowledge for understanding the phenomena occurring within the cold-cap.

This work is a part of the research supported by Japan Nuclear Fuel Limited with Grant-in-Aid by the Ministry of Economy, Trade and Industry.

\section{References}

1. N. Nakagiri, T. Miyata, Evaluation of value for hydrogen release from high-level liquid waste, (IV) - hydrogen release rate for gamma-ray radiolysis of simulated Purex waste solutions, J. At. Energy Soc. Jpn. 39, 563 (1998)

2. T. Murakami, Immobilization of high level radioactive waste in ceramic waste forms, J. Cryst. Soc. Jpn. 25, 168 (1983)

3. H. Matzke, E. Vernaz, Thermal and physicochemical properties important for the long term behavior of nuclear waste glasses, J. Nucl. Mater. 201, 295 (1993)

4. R. Pokorny, P. Hrma, Model for the conversion of nuclear waste melter feed to glass, J. Nucl. Mater. 445, 190 (2014)

5. R. Pokorny et al., Melting of glass batch: model for multiple overlapping gas-evolving reactions, Thermochim. Acta 541, $8(2012)$

6. J. Chun et al., Cold-cap reactions in vitrification of nuclear waste glass: experiments and modeling, Thermochim. Acta 559, 32 (2013)

7. R. Pokorny, P. Hrma, Mathematical modeling of cold cap, J. Nucl. Mater. 429, 245 (2012)

8. K.S. Chun, S.H. Lee, Vitrification of highly active liquid waste(I) (thermal decomposition of nitrates and additives for glass-making), J. Korean Nucl. Soc. 9, 211 (1977) 
9. K.S. Chun, J.B. Morris, Vitrification of highly active liquid waste(II) (the thermal decomposition of HARVEST feed slurries and the characterization of the product), J. Korean Nucl. Soc. 11, 211 (1979)

10. M. Benedict, T.H. Pigford, H.W. Levi, Nuclear chemical engineering (McGraw-Hill Education, 1981), 2nd ed.
11. E.S. Freeman, The kinetics of the thermal decomposition of sodium nitrate and of the reaction between sodium nitrite and oxygen, J. Phys. Chem. 60, 1487 (1956)

12. B.D. Bond, P.W.M. Jacobs, The thermal decomposition of sodium nitrate, J. Chem. Soc. A, 1966, 1265 (1966)

13. O. Abe et al., The reaction of sodium nitrite with silica, Bull. Chem. Soc. Jpn. 56, 428 (1983)

Cite this article as: Kota Kawai, Tatsuya Fukuda, Yoshio Nakano, Kenji Takeshita, Thermal decomposition analysis of simulated high-level liquid waste in cold-cap, EPJ Nuclear Sci. Technol. 2, 44 (2016) 